\title{
RESEARCH
}

\section{Epidural anesthesia and hypotension in pheochromocytoma and paraganglioma}

\author{
Douglas Wiseman1,*, James D McDonald(D1,*, Dhaval Patel1, Electron Kebebew², Karel Pacak³ and Naris Nilubol1 \\ ${ }^{1}$ National Cancer Institute, National Institutes of Health, Bethesda, Maryland, USA \\ 2Stanford University School of Medicine, Stanford, California, USA \\ ${ }^{3}$ Eunice Kennedy Shriver National Institute of Child Health and Human Development, National Institutes of Health, Bethesda, Maryland, USA \\ Correspondence should be addressed to N Nilubol: naris.nilubol@nih.gov \\ *(D Wiseman and J D McDonald contributed equally to this work)
}

\begin{abstract}
Postoperative hypotension frequently occurs after resection of pheochromocytoma and/or paraganglioma (PPGLs). Epidural anesthesia (EA) is often used for pain control in open resection of these tumors; one of its side effects is hypotension. Our aim is to determine if EA is associated with an increased risk of postoperative hypotension after open resection of PPGLs. We conducted a retrospective review of patients who underwent open resection of PPGLs at the National Institutes of Health from 2004 to 2019. Clinical and perioperative parameters were analyzed by the use of EA. The primary endpoint was postoperative hypotension. Ninety-seven patients (46 female and 51 male; mean age, 38.5 years) underwent open resection of PPGLs and 69 (71.1\%) received EA. Patients with EA had a higher rate beta-blocker use $(79.7 \%$ vs $57.1 \%, P=0.041)$, metastasis (69.6\% vs $39.3 \%, P=0.011)$, and were more frequently hypotensive after surgery $(58.8 \%$ vs $25.0 \%, P=0.003$ ) compared to those without EA. Patients with postoperative hypotension had higher plasma normetanephrines than those without ( 7.3 fold vs 4.1 fold above the upper limit of normal, $P=0.018)$. Independent factors associated with postoperative hypotension include the use of beta-blockers ( $\mathrm{HR}=3.35(95 \% \mathrm{Cl}: 1.16-9.67), P=0.026)$ and $\mathrm{EA}(\mathrm{HR}=3.49(95 \% \mathrm{Cl}: 1.25-9.76), P=0.017)$. Data from this retrospective study suggest that, in patients with open resection of PPGLs, EA is an independent risk factor for early postoperative hypotension. Special caution is required in patients on beta-blockade. A prospective evaluation with standardized protocols for the use of EA and management of hemodynamic variability is necessary.
\end{abstract}

$\begin{aligned} & \text { Key Words } \\ & \text { - } \text { epidurals } \\ & \text { - pheochromocytoma } \\ & \text { - paraganglioma } \\ & \text { - SDHB }\end{aligned}$

Endocrine-Related Cance (2020) 27, 519-527

\section{Introduction}

Pheochromocytomas and paragangliomas (PPGLs) are rare, catecholamine-secreting tumors arising from the chromaffin cells of the adrenal medulla and extra-adrenal neural crest tissues, which run from the skull base to the pelvis. The estimated incidence of these tumors is up to 0.8 in 100,000 persons per year, with pheochromocytomas comprising $80-85 \%$ of such cases and paragangliomas the other 15-20\% (Beard et al. 1983, Lenders et al. 2005). The definitive therapy for localized PPGLs is surgical resection, with the goal to reduce morbidity and mortality related to metastatic disease and long-term exposure to excess catecholamines. Laparoscopic resection is preferred when the location and size are amenable to a minimally invasive approach. However, open resection is
C) 2020 Society for Endocrinology Published by Bioscientifica Ltd. Printed in Great Britain 
recommended for larger and/or locally invasive adrenal pheochromocytomas or multifocal tumors, including metastases (Lenders et al. 2014).

The use of epidural anesthesia (EA) has become more routine as it has been shown to reduce postoperative pain and narcotic use. EA was also shown to reduce major cardiovascular complications and respiratory failure in open abdominal aortic surgery (Park et al. 2001). However, a common complication of EA is hypotension due to decreased peripheral vascular tone, which may occur up to $33 \%$ of the time (Carpenter et al. 1992). This is an especially important consideration when using EA for open resection of PPGLs, as these patients will routinely have significant hemodynamic fluctuations and postoperative hypotension related to perioperative alphaadrenoceptor blockade and abrupt reduction in circulating catecholamine levels (Bruynzeel et al. 2010). This study aims to determine EA's safety for use in open resection of subdiaphragmatic PPGL; specifically, we evaluated whether the use of EA during PPGL resection is associated with an increased risk of postoperative hypotension and complications from fluid overload.

\section{Methods}

This is a retrospective analysis of patients who had open resection of subdiaphragmatic PPGL from 2004 to 2019 at the National Cancer Institute and the Eunice Kennedy Shriver National Institute of Child Health and Human Development of the National Institutes of Health (NIH). The diagnosis was made preoperatively by biochemical profile and anatomic and functional imaging studies (Lenders et al. 2014), and it was confirmed by histopathology. Patients were excluded if they had incomplete medical records $(n=3)$ or an intervention other than open abdominal/retroperitoneal surgery for the extirpation of PPGL $(n=98)$. The study was approved by the Office of Human Research Protections at NIH. All patients provided written consent.

The use of epidural anesthesia was determined at the preoperative anesthesia visit and were determined based on patient surgical history, underlying diagnosis, and patient preference. Patients with von Hippel-Lindau (VHL) are not routinely offered the use of EA due to risk of bleeding from spinal hemangioblastomas that are common in patients with VHL, additionally, patients who have a history of prior spinal instrumentation or surgery, as well as those patients with known spinal metastases are not offered EA. We also included patients who deferred the use of EA as well as those planned laparoscopic resections that required conversion to open in order to safely complete the operation in the cohort as those who did not receive $\mathrm{EA}$.

In those patients who received EA, the epidural was placed in the intervertebral space from T8 to T9 preoperatively before induction. It was maintained intraoperatively with $0.0625-0.5 \%$ bupivacaine with or without fentanyl $(0.05 \mathrm{mg} / \mathrm{mL})$. Postoperatively, patients who did not receive EA had their pain controlled with intravenous and oral opioids, while patients who received EA had their pain controlled with patient-controlled EA. Basal EA was achieved by continuous infusion that was administered to all patients with EA and was titrated to achieve optimal pain control while maintaining blood pressure sufficient to provide adequate tissue perfusion (mean arterial pressure (MAP) $>60 \mathrm{mmHg}$ ) and urine output. Patients with EA could self-administer a bolus dose with lockout times set and adjusted exclusively at the discretion of the anesthesia team.

Perioperative data were collected by reviewing each patient's medical record. Preoperative data collected included patient demographics, preoperative biochemical profile, germline mutation status, tumor types and characteristics, the use of EA, the use of preoperative intravenous crystalloid (IVF), and alpha-adrenoceptor blockade and anti-hypertensive medication(s). PPGLs were considered biochemically active if patients had elevated preoperative plasma or 24 -h urine fractionated metanephrines or normetanephrines above the upper limit of normal (ULN). We defined multifocal tumors as the presence of two or more primary PPGLs and the absence of definitive clinical or pathologic evidence of metastasis or, in the case of pheochromocytoma, bilateral disease that had been noted. All patients treated at the NIH Clinical Center were admitted at least one night before surgery because most traveled from afar.

Intraoperative hemodynamics, volume of IVF administered, estimated blood loss, and transfusion requirement data were collected. The assessed postoperative parameters included the need for vasopressor(s); IVF within the first $24 \mathrm{~h}$ after surgery; hypotension (MAP $\leq 60 \mathrm{mmHg}$ ); the discontinuation of EA secondary to hypotension; clinical features associated with volume overload, such as patient's change in weight (maximum postoperative weight minus preoperative weight, in kgams), the use of diuretics postoperatively; hypoxia in the absence of other obvious causes and delayed return of bowel function (determined by time to return of bowel function, in days); and length of stay,
C) 2020 Society for Endocrinology Published by Bioscientifica Ltd. Printed in Great Britain 
in days. We defined intraoperative hypotension as any reading of a MAP $\leq 60 \mathrm{mmHg}$ (Kramer et al. 2009) in the anesthesia intraoperative record excluding the time of induction. Postoperative hypotension was defined as any reading from the ICU continuous flowsheet record of a MAP $\leq 60 \mathrm{mmHg}$ on invasive BP monitoring, any incidence noted was then further interrogated to confirm that it was indeed truly hypotension and not a technical error or recording error.

Management of perioperative hemodynamic fluctuations in patients who have undergone resection of PPGL at the NIH is driven by our institutional guidelines. The approach has been well-structured to make sure team members from anesthesia to critical-care teams adhere to these specific guidelines of treating patients with PPGL and postoperative hypotension. The bolus IV infusion with crystalloid is given primarily. Next, the epidural infusion rate is reduced or discontinued if patients do not respond to volume infusion adequately. Vasopressive agents are only given in those refractory to crystalloid infusion and discontinuation of epidural. However, in spite of these guidelines, there is some variability in the management of hemodynamic fluctuations because each patient may require different medications to achieve the optimal result. Because the need for intensive hemodynamic monitoring and treatments occurred solely within the duration of the intensive care unit (ICU) stay, the postoperative evaluation period in this study was defined as the time that patients were admitted in the ICU.

Tumor size was defined as the maximum linear tumor dimension, in centimeters, taken from resected specimen(s) of the largest PPGL. The total volume of all tumors (Wapnir et al. 2001) (volume $\left.=\pi / 6 \sum_{i=1}^{n}(l w h)_{i}\right)$ and the number of tumors present were also analyzed.

The primary endpoint was postoperative hypotension.

\section{Statistical analysis}

Group comparisons were performed using $\chi^{2}$ tests (Fisher 1922) for dichotomous variables and the MannWhitney $U$-test (Mann \& Whitney 1947) for continuous variables. Two-tailed $P<0.05$ was considered statistically significant. Multivariate Cox proportional hazard regression (Cox 1972) modeling was performed for variables with $P$ values $\leq 0.1$ in univariate analyses for postoperative hypotension. All statistical analyses were calculated with IBM SPSS Software, Windows version 25.0 (IBM Corp).

\section{Results}

Sixty-nine of 97 (71.1\%) patients had EA placed for open resection of PPGL. Cohort demographics and clinical characteristics are summarized in Tables 1 and 2 . Of those 28 patients who did not receive EA, its use was contraindicated in 11 patients because of underlying VHL, 3 patients with prior spine surgery, and 1 patient with spinal metastasis. Of the remaining 13 who did not receive EA, 6 patients deferred the use of EA, 6 underwent a planned laparoscopic resection that was converted to open resection, and 1 patient had a failed placement of the epidural. Demographics and clinical characteristics were similar between patients with and without EA, except that those patients who received EA had higher rates of metastasis $(69.6 \%(n=48 / 69)$ vs $39.3 \%(n=11 / 28)$, $P=0.011)$, beta-blocker (BB) use $(79.7 \%(n=55 / 69)$ vs $57.1 \%(n=16 / 28), P=0.041)$, and reoperative surgery (72.5\% $(n=50 / 69)$ vs $46.4 \%(n=13 / 28), P=0.020)$ and less preoperative metyrosine use $(42.0 \%(n=29 / 69)$ vs $66.7 \%$ $(n=18 / 27), P=0.041)$. The median number of tumors in the EA cohort was greater than the median number of tumors in the cohort that did not receive EA (2.0 (1.0-3.0) vs 1.0 (1.0-2.0) tumors, $P=0.021$ ).

Intraoperative and postoperative hypotension occurred frequently in our cohort $(72.9 \%, n=62 / 85$ and $49.0 \%, n=47 / 96$, respectively). EA was stopped because of postoperative hypotension in $14.5 \%(n=10 / 69)$ of cases. Patients who received EA had a significantly higher rate of postoperative hypotension $(58.8 \%(n=40 / 68)$ vs $25.0 \%$ $(n=7 / 28), P=0.003)$ on univariate analysis. However, we found no statistically significant differences in the use of postoperative vasopressors $(P=0.502)$, the volume of IVF in the first $24 \mathrm{~h}$ after surgery $(P=0.443)$, postoperative weight gain $(P=0.203)$, the rate of hypoxia $(P=0.773)$, or the use of diuretics $(P=0.599)$ (Table 2).

We assessed the characteristics of patients who developed postoperative hypotension and found that they had a significantly higher median number of tumors (2 (1-3) vs $1(1-2)$ tumors, $P=0.029)$ and higher plasma normetanephrines than those without hypotension (median 7.3 fold (3.2-17.3) vs median 4.1 fold (1.8-8.7) above the ULN, $P=0.018$ ). Additionally, we also found that patients who developed postoperative hypotension received more crystalloid in the first $24 \mathrm{~h}$ after surgery (4058 (2871-5270) $\mathrm{mL}$ vs 2872 (2385-3544) $\mathrm{mL}, P=0.001)$ and had greater weight gain $(6.0 \pm 3.7 \mathrm{~kg}$ vs $2.6 \pm 3.7 \mathrm{~kg}$, $P=0.004$ ) from preoperative weight (Table 3). Fifty-seven percent of patients taking BBs before the operation experienced postoperative hypotension vs $42.8 \%$ of 
Table 1 Patient demographics and clinical characteristics by the use of epidural anesthesia.

\begin{tabular}{|c|c|c|c|c|}
\hline \multirow[b]{2}{*}{ Variable } & \multirow[b]{2}{*}{ All $(n=97)$} & \multicolumn{2}{|c|}{ Epidural anesthesia } & \multirow[b]{2}{*}{$\boldsymbol{P}$} \\
\hline & & Yes, median (IQR) & No, median (IQR) & \\
\hline Age (years), mean \pm S.D. & 97 & $38.1 \pm 15.2$ & $39.5 \pm 14.1$ & 0.679 \\
\hline Chromogranin A & 97 & 315 (149-723) & $646(251-1220)$ & 0.144 \\
\hline 24-h urine NMN f-ULN & 85 & $3.0(1.0-9.3)$ & $2.2(1.0-4.6)$ & 0.753 \\
\hline 24-h urine MN f-ULN & 84 & $0.4(0.2-0.7)$ & $0.6(0.3-1.8)$ & 0.186 \\
\hline Plasma NMN f-ULN & 97 & $5.1(2.0-15.6)$ & $5.9(1.4-9.8)$ & 0.836 \\
\hline Plasma MN f-ULN & 96 & $0.6(0.3-1.0)$ & $0.5(0.4-2.0)$ & 0.528 \\
\hline Plasma dopamine f-ULN & 93 & $0.8(0.4-1.6)$ & $0.7(0.4-1.4)$ & 0.397 \\
\hline Tumor max dimension (cm) & 97 & $3.7(2.5-6.3)$ & $3.9(2.7-4.5)$ & 0.924 \\
\hline Number of tumors & 97 & $2.0(1.0-3.0)$ & $1.0(1.0-2.0)$ & 0.021 \\
\hline Total tumor volume $\left(\mathrm{cm}^{3}\right)$ & 97 & $14.5(4.3-41.0)$ & $11.5(4.5-34.9)$ & 0.811 \\
\hline Duration of $\alpha$-blockade (days) & 97 & $38(17-67)$ & $21(17-30)$ & 0.075 \\
\hline Number of BP medications & 97 & $2(2-3)$ & $2(2-3)$ & 0.564 \\
\hline Preoperative IVF hydration (mL), mean \pm S.D. & 95 & $1244 \pm 618$ & $1404 \pm 596$ & 0.248 \\
\hline Estimated blood loss (mL) & 95 & $250(100-640)$ & $400(125-1000)$ & 0.175 \\
\hline Surgery duration (min) & 97 & $296(209-305)$ & $303(188-303)$ & 0.774 \\
\hline IO crystalloid (mL) & 97 & $4500(3500-6000)$ & $4000(3000-6600)$ & 0.285 \\
\hline 24-h postoperative IVF (mL) & 97 & $3300(2700-4700)$ & $3200(2300-4500)$ & 0.443 \\
\hline $\begin{array}{l}\text { Increase in postoperative weight (kg), } \\
\text { mean } \pm \text { S.D. }\end{array}$ & 97 & $5.7 \pm 4.0$ & $4.2 \pm 3.5$ & 0.117 \\
\hline Return of bowel function (days) & 97 & $4.0(3.0-6.0)$ & $3.5(3.0-5.0)$ & 0.349 \\
\hline Length of stay (days) & 97 & $7.0(6.0-9.0)$ & $7.0(5.3-8.8)$ & 0.560 \\
\hline
\end{tabular}

BP, antihypertensive; f-ULN, fold above upper limit of normal; IO, intraoperative; IQR, interquartile range; IVF, intravenous fluid; max, maximum; $\mathrm{MN}$, metanephrines; NMN, normetanephrine. Bold indicates statistical significance, $P<0.05$.

patients on BBs who did not experience postoperative hypotension $(P=0.011)$ (Table 4$)$.

The statistically significant independent factors that were associated with postoperative hypotension, demonstrated by multivariate Cox proportional hazard regression analysis included the use of $\mathrm{BBs}(\mathrm{HR}=3.35$ (95\% CI: $1.16-9.67), P=0.026)$ and EA (HR=3.49 (95\% CI: 1.25-9.76), $P=0.017$ ) (Table 5).

\section{Discussion}

In this study, we aimed to determine whether the use of EA was associated with an increased risk of postoperative hypotension and complications related to the treatment of postoperative hypotension in patients undergoing open resection for PPGL. We found that postoperative hypotension occurred in $49 \%$ of all cases. Not surprisingly, patients with postoperative hypotension required a larger volume of IVF and had higher weight gain. The use of BBs preoperatively and EA were independent predictors of postoperative hypotension. The majority (66\%) of patients in our cohort had an underlying germline mutation associated with PPGL, and even more frequently than that, $70 \%$ who received EA had either multifocal or metastatic disease. It may appear that this cohort is biased toward more advanced or aggressive disease; however, this is the group of patients most likely to be offered EA in clinical practice at the time of surgery because these multifocal/metastatic tumors require an open approach to achieve an adequate oncologic resection. While the findings of our study may not be generalizable to all patients with PPGL, it does report valuable information for those patients with PPGL who will require an open operation with a consideration of EA use. Data regarding the use of EA in patients receiving open resection for PPGL are scarce and an analysis of our institutional experience provides significant insight into the use of EA in this patient population.

To our knowledge, this is the first study examining EA use in the context of open resection of PPGL with postoperative hypotension as a primary endpoint in a large cohort of this rare disease. The recent study ( $\mathrm{Li}$ et al. 2018) examined the perioperative complications using the Clavien-Dindo classification in open resection of pheochromocytoma in patients with GETA alone vs a combination of GETA and EA. That study found significantly fewer complications in the combined group and, more specifically, no difference in the two groups for hemodynamic fluctuations ( $87 \%$ vs $93 \%, P=0.347)$, where hemodynamic fluctuations were defined as: (1) systolic blood pressure $\geq 200 \mathrm{mmHg}$ or increased to more (c) 2020 Society for Endocrinology Published by Bioscientifica Ltd. Printed in Great Britain 
Table 2 Patient characteristics by the use of epidural anesthesia.

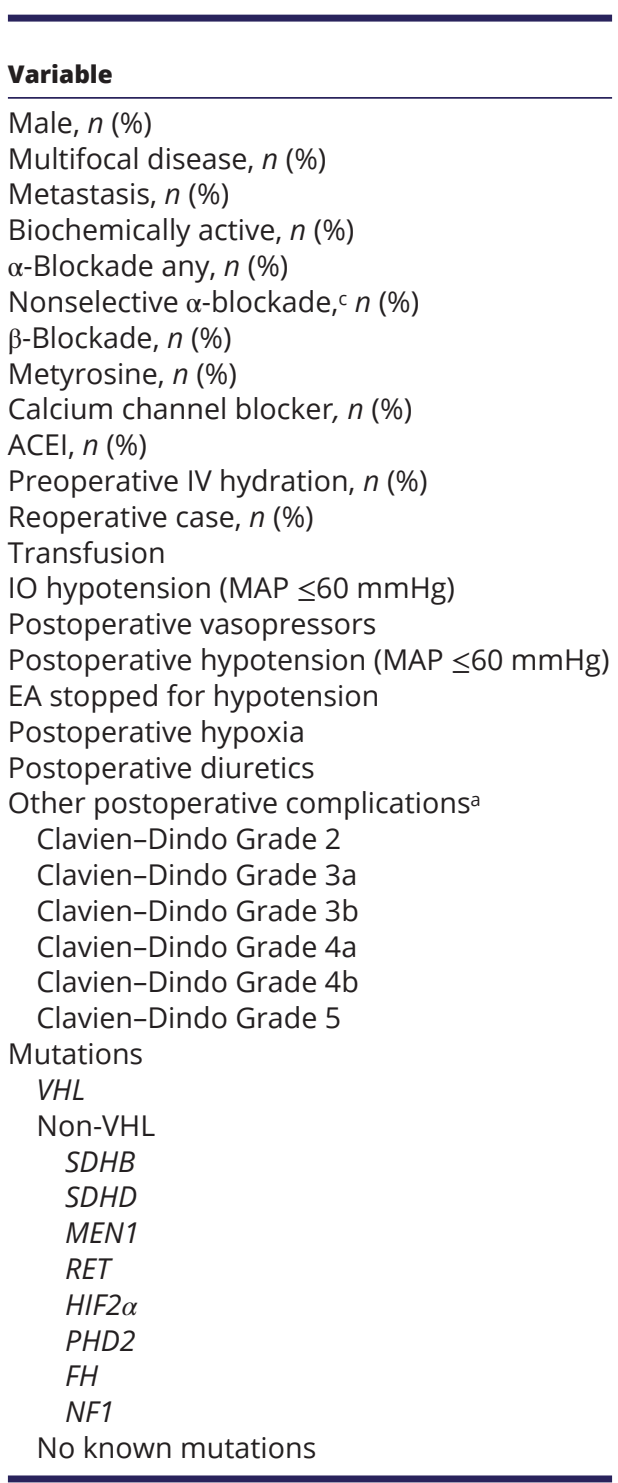

\begin{tabular}{c} 
All $(n=97)$ \\
\hline $51(52.6)$ \\
$37(38.1)$ \\
$59(60.8)$ \\
$89(91.8)$ \\
$88(90.7)$ \\
$72(80.0)$ \\
$71(73.2)$ \\
$47(49.0)$ \\
$21(21.6)$ \\
$6(6.2)$ \\
$86(88.7)$ \\
$63(64.9)$ \\
$16(16.8)$ \\
$62(72.9)$ \\
$12(12.6)$ \\
$47(49.0)$ \\
$10(10.3)$ \\
$19(20.7)$ \\
$23(23.7)$ \\
$14(14.4)$ \\
9 \\
2 \\
1 \\
1 \\
0 \\
1 \\
$12(12.4)$ \\
$85(87.6)$ \\
$46(26.8)$ \\
$4(4.1)$ \\
$3(4.4)$ \\
$11(12.2)$ \\
$1(1.0)$ \\
\\
$1(2.1)$ \\
\\
\hline \\
\end{tabular}

\begin{tabular}{|c|c|c|}
\hline \multicolumn{2}{|c|}{ Epidural anesthesia } & \multirow[b]{2}{*}{$\boldsymbol{P}$} \\
\hline Yes $(n=69)$ & No $(n=28)$ & \\
\hline 35 (50.7) & $16(57.1)$ & 0.656 \\
\hline $28(40.6)$ & $9(32.1)$ & 0.495 \\
\hline 48 (69.6) & $11(39.3)$ & 0.011 \\
\hline 63 (91.3) & 26 (92.9) & 1.000 \\
\hline $61(88.4)$ & $27(96.4)$ & 0.440 \\
\hline 47 (74.6) & $25(92.6)$ & 0.082 \\
\hline 55 (79.7) & $16(57.1)$ & 0.041 \\
\hline $29(42.0)$ & $18(66.7)$ & 0.041 \\
\hline $16(23.2)$ & 5 (17.9) & 0.786 \\
\hline $5(7.2)$ & $1(3.6)$ & 0.669 \\
\hline $60(87.0)$ & $26(92.9)$ & 0.503 \\
\hline $50(72.5)$ & $13(46.4)$ & 0.020 \\
\hline $8(11.8)$ & 8 (29.6) & 0.064 \\
\hline 45 (72.6) & $17(73.9)$ & 1.000 \\
\hline 10 (14.5) & $2(7.7)$ & 0.502 \\
\hline $40(58.8)$ & $7(25.0)$ & 0.003 \\
\hline $10(14.5)$ & $0(0)$ & 0.058 \\
\hline $13(19.4)$ & $6(24.0)$ & 0.773 \\
\hline $15(21.7)$ & $8(28.6)$ & 0.599 \\
\hline $9(13.0)$ & 5 (17.9) & 0.537 \\
\hline 6 & 3 & \\
\hline 1 & 1 & \\
\hline 1 & 0 & \\
\hline 0 & 1 & \\
\hline 0 & 0 & \\
\hline 1 & 0 & \\
\hline $1(1.4)$ & $11(39.3)$ & $<0.001^{b}$ \\
\hline 68 (98.6) & $17(60.7)$ & \\
\hline 22 (31.9) & $4(14.3)$ & \\
\hline $3(4.3)$ & $1(3.6)$ & \\
\hline $3(4.3)$ & $1(3.6)$ & \\
\hline $2(2.9)$ & $1(3.6)$ & \\
\hline $10(14.5)$ & $1(3.6)$ & \\
\hline $1(1.4)$ & $0(0)$ & \\
\hline $2(2.9)$ & $0(0)$ & \\
\hline $0(0)$ & $1(3.6)$ & \\
\hline $25(36.2)$ & $8(28.6)$ & \\
\hline
\end{tabular}

ACEI, angiotensin-converting-enzyme inhibitor; EA, epidural anesthesia; IO, intraoperative; IV, intravenous; MAP, mean arterial pressure; VHL, von Hippel-Lindau syndrome. Bold indicates statistical significance, $P<0.05$. aspiration pneumonia $(n=2)$, gastrointestinal bleed $(n=1)$, hypertension $(n=2)$, intra-abdominal abscess $(n=1)$, myocardial infarction/death $(n=1)$, pulmonary embolus $(n=1)$, urinary tract infection $(n=2)$, wound dehiscence $(n=1)$, wound infection ( $n=3)$; bVHL compared to all other mutations; cNonselective = phenoxybenzamine, Selective = doxazosin, prazosin, or terazosin.

than $30 \%$ above baseline; (2) systolic blood pressure $\leq 90$ mmHg; (3) heart rate $\geq 110 \mathrm{bpm}$; and (4) heart rate $\leq 50$ bpm. However, this study did not specifically discuss the rate of hypotension. In our series, intraoperative and postoperative hypotension occurred in 73 and $49 \%$ of all cases, respectively. Other studies have demonstrated comparable occurrences of intraoperative hypotension, from 41\% (Kramer et al. 2009) to 81\% (Butz et al. 2017), in open resection of pheochromocytoma. We believe that postoperative hypotension is a clinically meaningful endpoint, as patients with postoperative hypotension required significantly more IVF in the first $24 \mathrm{~h}$ after surgery, which led to greater weight gain, EA discontinuation, and increased vasopressor treatment in this study to maintain adequate tissue perfusion.

Predictors of hypotension on univariate analysis were elevated plasma normetanephrine, number of tumors, use of BBs, and EA use. However, only the use of BBs and EA use were significant on multivariable analysis. One study found that higher adrenergic levels (defined as the highest percentage in any of the measured urine or plasma catecholamines or catecholamine metabolites) $(\geq 501 \%$ (c) 2020 Society for Endocrinology Published by Bioscientifica Ltd. Printed in Great Britain 
Table 3 Cohort characteristics by postoperative hypotension.

\begin{tabular}{|c|c|c|c|c|}
\hline \multirow[b]{2}{*}{ Variable } & \multirow[b]{2}{*}{ All $(n=96)$} & \multicolumn{2}{|c|}{ Postoperative hypotension } & \multirow[b]{2}{*}{$\boldsymbol{P}$} \\
\hline & & No, median (IQR) & Yes, median (IQR) & \\
\hline Age (years), mean \pm S.D. & 96 & $37.8 \pm 14.5$ & $37.5 \pm 15.6$ & 0.937 \\
\hline Chromogranin A & 96 & $196(134-893)$ & $328(163-776)$ & 0.520 \\
\hline 24-h urine NMN f-ULN & 85 & $2.8(1.1-3.6)$ & $5.0(1.1-9.9)$ & 0.175 \\
\hline 24-h urine MN f-ULN & 84 & $0.4(0.3-1.4)$ & $0.4(0.2-0.8)$ & 0.329 \\
\hline Plasma NMN f-ULN & 96 & $4.1(1.8-8.7)$ & $7.3(3.2-17.3)$ & 0.018 \\
\hline Plasma MN f-ULN & 96 & $0.5(0.4-1.1)$ & $0.5(0.4-0.7)$ & 0.797 \\
\hline Plasma dopamine f-ULN & 93 & $0.9(0.4-1.8)$ & $1.1(0.4-2.8)$ & 0.595 \\
\hline Tumor max dimension (cm) & 96 & $3.6(2.5-5.8)$ & $3.9(2.5-6.3)$ & 0.254 \\
\hline Number of tumors & 96 & $1(1-2)$ & $2(1-3)$ & 0.029 \\
\hline Total tumor volume $\left(\mathrm{cm}^{3}\right)$ & 96 & $13.8(4.6-45.3)$ & $15.78(3.8-56.9)$ & 0.369 \\
\hline Duration of $\alpha$-blockade (days) & 96 & $30.0(17.3-65.5)$ & $38.0(17.5-66.0)$ & 0.377 \\
\hline Number of BP medications, mean \pm S.D. & 96 & $2.3 \pm 0.9$ & $2.6 \pm 0.7$ & 0.140 \\
\hline Preopeartive MAP & 96 & $89.7(80.3-94.8)$ & $87.3(82-95)$ & 0.724 \\
\hline Preoperative SBP & 96 & $124(117-130)$ & 120 (115-128) & 0.361 \\
\hline $\begin{array}{l}\text { Preoperative IVF hydration }(\mathrm{mL}) \text {, mean } \pm \\
\text { S.D. }\end{array}$ & 95 & $1280 \pm 591$ & $1250 \pm 619$ & 0.823 \\
\hline Estimated blood loss (mL) & 95 & $300(100-800)$ & $300(100-800)$ & 0.736 \\
\hline Surgery duration (min) & 96 & 247 (189-386) & $312(242-365)$ & 0.446 \\
\hline IO crystalloid (mL) & 96 & $4300(3000-6150)$ & $4500(3500-6000)$ & 0.450 \\
\hline 24-h postoperative IVF (mL) & 96 & $2872(2385-3544)$ & $4058(2871-5270)$ & 0.001 \\
\hline $\begin{array}{l}\text { Increase in postoperative weight (kg), } \\
\text { mean } \pm \text { S.D. }\end{array}$ & 96 & $4.0 \pm 3.7$ & $6.4 \pm 3.8$ & 0.007 \\
\hline Return of bowel function (days) & 96 & $4.0(3.0-5.0)$ & $4.0(2.0-6.0)$ & 0.425 \\
\hline Length of stay (days) & 96 & $7.0(6.0-9.0)$ & $7.0(6.0-9.0)$ & 0.678 \\
\hline
\end{tabular}

BP, antihypertensive; f-ULN, fold above upper limit of normal; IO, intraoperative; IQR, interquartile range; IVF, intravenous fluid; MAP, mean arterial pressure; max, maximum; MN, metanephrines; NMN, normetanephrine; SBP, systolic blood pressure. Bold indicates statistical significance, $P<0.05$.

vs $\leq 500 \%$ ULN) predicted a greater need for vasopressor infusion for the treatment of hypotension after PPGL resection ( $8 \%$ vs $2 \%, P=0.01$ ) (Weingarten et al. 2017), but the association with EA was not evaluated. Because the initial treatment for postoperative hypotension in patients who have surgery for PPGL is IVF bolus, the primary endpoint in this study was postoperative hypotension regardless of treatments, as we specifically evaluated the role of EA use in postoperative hypotension. In addition, we did not combine the highest value of measured urine and plasma catecholamines and metabolites into graduated groups normalized by the ULN because it is more practical to evaluate each catecholamine metabolite separately. Guidelines for the preoperative management of a patient with PPGL (Lenders et al. 2014) include high sodium diet in the weeks leading up to surgery and continuous normal saline infusion starting the evening before surgery as a way to reverse blood volume contraction from high levels of circulating catecholamines with the goal of limiting rate of intraoperative and postoperative hypotension. However, when we analyzed postoperative hypotension relative to the volume of preoperative fluids administered, we observed no difference in the rate of postoperative hypotension.
Of the medications included in our study (selective and nonselective alpha-adrenoceptor blockers, BBs, calcium channel blockers, metyrosine, and angiotensinconverting-enzyme inhibitors) only BBs demonstrated statistical significance in both univariate and multivariate analyses when analyzed by our primary endpoint of hypotension. Surprisingly, alpha-adrenoceptor blockers were not a predictor of postoperative hypotension, and when a subgroup analysis was performed there was no difference in the rate of postoperative hypotension at different doses of alpha-adrenergic blockade. This is the first study implicating preoperative BB use as a risk factor for postoperative hypotension in the open resection of subdiaphragmatic PPGLs. Postoperative hypotension after PPGL resection is thought to be the result of a stepwise reduction in circulating catecholamines and decreased availability of alpha-adrenoceptors secondary to preoperative preparation with alpha-adrenoceptor blockade. BBs are added after alpha-adrenoceptor blockade in the preoperative management of patients with PPGL to control and minimize tachyarrhythmias (Pacak 2007). BBs are a heterogeneous class of drugs. Carvedilol and nebivolol may exacerbate hypotension due to their vasodilatory properties via $\alpha_{1}$-adrenergic (c) 2020 Society for Endocrinology Published by Bioscientifica Ltd. Printed in Great Britain 
Table 4 Clinical and perioperative parameters by postoperative hypotension.

\begin{tabular}{lc}
\hline & \\
Variable & All $(n=96)$ \\
\hline Male, Female (\%) & 96 \\
Multifocal disease: No, Yes (\%) & 96 \\
Metastasis: No, Yes (\%) & 96 \\
Biochemically active: No, Yes (\%) & 96 \\
$\alpha$-Blockade: No, Yes (\%) & 96 \\
Nonselective $\alpha$-blockade, Selective $\alpha$-blockade (\%) & 89 \\
$\beta$-Blockade: No, Yes (\%) & 96 \\
Metyrosine: No, Yes (\%) & 95 \\
Calcium channel blocker: No, Yes (\%) & 96 \\
ACEl: No, Yes (\%) & 96 \\
Preoperative IV hydration: No, Yes (\%) & 96 \\
Reoperative case: No, Yes (\%) & 96 \\
Mechanical bowel preparation: No, Yes (\%) & 96 \\
Transfusion: No, Yes (\%) & 95 \\
IO hypotension (MAP $\leq 60$ mmHg): No, Yes (\%) & 85 \\
Postoperative vasopressors: No, Yes (\%) & 94 \\
EA: No, Yes (\%) & 96 \\
EA stopped for postoperative hypotension: & 96 \\
No, Yes (\%) & 96 \\
Postoperative hypoxia: No, Yes (\%) & 96 \\
Postoperative diuretics: No, Yes (\%) & 96 \\
\hline & \\
\hline
\end{tabular}

\begin{tabular}{|c|c|c|}
\hline \multicolumn{2}{|c|}{ Postoperative hypotension } & \multirow[b]{2}{*}{$\boldsymbol{P}$} \\
\hline No $(n=49)$ & Yes $(n=47)$ & \\
\hline 30 (61.2), 19 (38.8) & 20 (42.6), $27(57.4)$ & 0.102 \\
\hline 35 (71.4), 14 (28.6) & $25(53.2), 22(46.8)$ & 0.091 \\
\hline $22(44.9), 27(55.1)$ & $16(34.0), 31(66.0)$ & 0.303 \\
\hline $9(18.4), 40(81.6)$ & $10(21.3), 37(78.7)$ & 0.269 \\
\hline $5(10.2), 44(89.8)$ & $4(8.5), 43(91.5)$ & 1.000 \\
\hline 36 (81.8), 8 (18.2) & $35(77.8), 10(22.2)$ & 0.793 \\
\hline $19(38.8), 30(61.2)$ & 7 (14.9), 40 (85.1) & 0.011 \\
\hline $24(50.0), 24(50.0)$ & $24(51.1), 23$ (48.9) & 1.000 \\
\hline 39 (79.6), 10 (20.4) & $36(76.6), 11(23.4)$ & 0.807 \\
\hline 45 (91.8), 4 (8.1) & 45 (95.7), 2 (4.3) & 0.678 \\
\hline $6(12.2), 43(87.8)$ & $5(10.6), 42(89.4)$ & 1.000 \\
\hline 18 (36.7), 31 (63.3) & $16(34.0), 31(66.0)$ & 0.833 \\
\hline 14 (28.6), 35 (71.4) & $8(17.0), 39(83.0)$ & 0.227 \\
\hline 39 (81.3), 9 (18.8) & $40(85.1), 7(14.9)$ & 0.785 \\
\hline 14 (35.0), 26 (65.0) & 9 (20.0), $36(80.0)$ & 0.146 \\
\hline $46(97.9), 1(2.1)$ & 36 (76.6), $11(23.4)$ & 0.004 \\
\hline 21 (42.9), 28(57.1) & 7 (14.9), 40 (85.1) & 0.003 \\
\hline 48 (100.0), $0(0.0)$ & 38 (80.9), 9 (19.1) & 0.007 \\
\hline 37 (78.7), 10 (21.3) & 36 (80.0), 9 (20.0) & 1.000 \\
\hline 40 (81.6), 9 (18.4) & $33(70.2), 14(29.8)$ & 0.235 \\
\hline
\end{tabular}

ACEI, angiotensin-converting-enzyme inhibitor; IO, intraoperative; IV, intravenous; MAP, mean arterial pressure. Bold indicates statistical significance, $P<0.05$.

antagonism (Leonetti \& Egan 2012, Poirier \& Tobe 2014) and $\beta_{3}$-agonistic and nitric oxide mechanisms (Fongemie \& Felix-Getzik 2015, Marketou et al. 2017), respectively. Like nebivolol, metoprolol and atenolol are $\beta_{1}$-selective adrenoceptor antagonists. However, they do not have appreciable vasodilatory properties (Egan et al. 2018). Because our patients were on several different types of BBs, vasodilatation is unlikely to be the only mechanism by which BBs increase the risk of postoperative hypotension. Non-vasodilating BBs reduce blood pressure or MAP, by reducing cardiac output (CO) via decreased heart rate (Messerli \& Grossman 2004). Vasodilatory BBs reduce MAP by reducing systemic vascular resistance (SVR) (Pedersen $\&$ Cockcroft 2007). Because MAP is directly proportional to $\mathrm{CO}$ and SVR $(\mathrm{MAP}=((\mathrm{CO} \times \mathrm{SVR}) / 80)+$ central venous pressure), a reduction in $\mathrm{CO}$ from a $\mathrm{BB}$ can further reduce

Table 5 Multivariate Cox proportional hazard regression analysis of clinical parameters for predicting postoperative hypotension in open subdiaphragmatic resection of PPGL.

\begin{tabular}{|c|c|c|c|c|}
\hline \multirow[b]{2}{*}{ Clinical parameters } & \multirow[b]{2}{*}{ Hazard ratio } & \multicolumn{2}{|c|}{$95 \% \mathrm{Cl}$ for $\exp (\mathrm{B})$} & \multirow[b]{2}{*}{$\boldsymbol{P}$} \\
\hline & & Lower & Upper & \\
\hline Epidural anesthesia & 3.49 & 1.25 & 9.76 & 0.017 \\
\hline$\beta$-blockade & 3.35 & 1.16 & 9.67 & 0.026 \\
\hline Multifocal tumors & 2.46 & 0.97 & 6.24 & 0.058 \\
\hline
\end{tabular}

Bold indicates statistical significance, $P<0.05$.

C) 2020 Society for Endocrinology Published by Bioscientifica Ltd. Printed in Great Britain
MAP in patients receiving adequate alpha-adrenoceptor blockade. An additional reduction in SVR from EA in patients receiving both $\mathrm{BB}$ and alpha-adrenoceptor blockade can predispose patients to a higher rate of postoperative hypotension and this provides an explanation to our finding between the association of preoperative beta blockers use and postoperative hypotension in the setting of EA use.

Rates of hypotension related to epidural use for open abdominal operations range from 15 to 33\% (Carpenter et al. 1992, Tarkkila \& Isola 1992). However, these studies did not control for resection of abdominal PPGL. EA increased the risk of postoperative hypotension on univariate analysis and retained statistical significance when multivariable analysis was performed. The impact of EA on postoperative hypotension is likely due to decreased peripheral vascular tone (Carpenter et al. 1992), and when viewed in the setting of abrupt reduction in circulating catecholamines, as is the case with resection of PPGL, in patients who are commonly on preoperative beta-blockade, the risk of postoperative hypotension is not trivial and explains why our observed rate of hypotension was closer to $50 \%$.

Our study has several limitations. It is subject to the pitfalls associated with any retrospective study, particularly patient selection as our cohort is a highly skewed representation of patients with PPGL as many of 
our patients have advanced disease, underlying familial syndrome, or both. Another limitation is that the sample size is small for these rare tumors, and type II errors may be present. These limitations might be overcome with a multi-institutional prospective study comparing efficacy and safety of EA in the open resection of abdominal tumors. Such a study could compare differences in PPGL and non-catecholamine secreting tumors in order to better define complication rates related to EA in these groups. Although most patients received the same concentrations of bupivacaine and fentanyl, the perioperative EA infusion rates and boluses optimized for pain control varied among our patients and were chosen at the discretion of our anesthesiologists, as well provider variability in the management of perioperative hemodynamic fluctuations. Additionally, there is no standard for defining some of the variables we studied, and the definition of hypotension has varied in some of the aforementioned studies. Despite our study's shortcomings, it does implicate BBs and EA use as statistically independent predictors of postoperative hypotension in the open resection of PPGLs and should help select patients for EA when undergoing these procedures.

\section{Conclusions}

In conclusion, our data from this retrospective study suggest that EA is an independent risk factor for early postoperative hypotension in patients undergoing open resection of PPGLs, and consequently, it should be used with caution in these operations. In these surgical patients needing BBs for preoperative control of tachyarrhythmias, mindful postoperative planning for resuscitation should be followed due to the increased risk of hypotension. A prospective randomized study with standardized protocols for the use of EA, perioperative preparation, and management of hemodynamic variability in this patient population is necessary to make further judgments and statements on the safety efficacy in the use of EA in patient with PPGL.

\section{Declaration of interest}

The authors declare that there is no conflict of interest that could be perceived as prejudicing the impartiality of the research reported.

\section{Funding}

This research was supported by the Intramural Research Program of the National Cancer Institute and the Eunice Kennedy Shriver National Institute of Child Health and Human Development of NIH.

(C) 2020 Society for Endocrinology Published by Bioscientifica Ltd. Printed in Great Britain

\section{References}

Beard CM, Sheps SG, Kurland LT, Carney JA \& Lie JT 1983 Occurrence of pheochromocytoma in Rochester, Minnesota, 1950 through 1979. Mayo Clinic Proceedings 58 802-804.

Bruynzeel H, Feelders RA, Groenland TH, van den Meiracker AH, van Eijck CH, Lange JF, de Herder WW \& Kazemier G 2010 Risk factors for hemodynamic instability during surgery for pheochromocytoma. Journal of Clinical Endocrinology and Metabolism 95 678-685. (https:// doi.org/10.1210/jc.2009-1051)

Butz JJ, Weingarten TN, Cavalcante AN, Bancos I, Young Jr WF, McKenzie TJ, Schroeder DR, Martin DP \& Sprung J 2017 Perioperative hemodynamics and outcomes of patients on metyrosine undergoing resection of pheochromocytoma or paraganglioma. International Journal of Surgery 46 1-6. (https://doi. org/10.1016/j.ijsu.2017.08.026)

Carpenter RL, Caplan RA, Brown DL, Stephenson C \& Wu R 1992 Incidence and risk factors for side effects of spinal anesthesia. Anesthesiology 76 906-916. (https://doi.org/10.1097/00000542199206000-00006)

Cox DR 1972 Regression models and life-tables. Journal of the Royal Statistical Society: Series B 34 187-202. (https://doi. org/10.1111/j.2517-6161.1972.tb00899.x)

Egan B, Flack J, Patel M \& Lombera S 2018 Insights on beta-blockers for the treatment of hypertension: a survey of health care practitioners. Journal of Clinical Hypertension 20 1464-1472. (https://doi. org/10.1111/jch.13375)

Fisher RA 1922 On the Interpretation of chi-squared from contingency tables, and the calculation of. Journal of the Royal Statistical Society $\mathbf{8 5}$ 87-94. (https://doi.org/10.2307/2340521)

Fongemie J \& Felix-Getzik E 2015 A review of nebivolol pharmacology and clinical evidence. Drugs 75 1349-1371. (https://doi.org/10.1007/ s40265-015-0435-5)

Kramer CK, Leitao CB, Azevedo MJ, Canani LH, Maia AL, Czepielewski M, Paggi A, Rodrigues TC, Silveiro SP, Friedman R, et al. 2009 Degree of catecholamine hypersecretion is the most important determinant of intra-operative hemodynamic outcomes in pheochromocytoma. Journal of Endocrinological Investigation 32 234-237. (https://doi.org/10.1007/BF03346458)

Lenders JW, Eisenhofer G, Mannelli M \& Pacak K 2005 Phaeochromocytoma. Lancet 366 665-675. (https://doi.org/10.1016/ S0140-6736(05)67139-5)

Lenders JW, Duh QY, Eisenhofer G, Gimenez-Roqueplo AP, Grebe SK, Murad MH, Naruse M, Pacak K, Young Jr WF \& Endocrine Society 2014 Pheochromocytoma and paraganglioma: an endocrine society clinical practice guideline. Journal of Clinical Endocrinology and Metabolism 99 1915-1942. (https://doi.org/10.1210/jc.2014-1498)

Leonetti G \& Egan CG 2012 Use of carvedilol in hypertension: an update. Vascular Health and Risk Management 8 307-322. (https://doi. org/10.2147/VHRM.S31578)

Li N, Kong H, Li SL, Zhu SN \& Wang DX 2018 Combined epiduralgeneral anesthesia was associated with lower risk of postoperative complications in patients undergoing open abdominal surgery for pheochromocytoma: a retrospective cohort study. PLOS ONE 13 e0192924. (https://doi.org/10.1371/journal.pone.0192924)

Mann HB \& Whitney DR 1947 On a test of whether one of two random variables is stochastically larger than the other. Annals of Mathematical Statistics 18 50-60. (https://doi.org/10.1214/ aoms/1177730491)

Marketou M, Gupta Y, Jain S \& Vardas P 2017 Differential metabolic effects of beta-blockers: an updated systematic review of nebivolol. Current Hypertension Reports 19 22. (https://doi.org/10.1007/s11906017-0716-3)

Messerli FH \& Grossman E 2004 Beta-blockers in hypertension: is carvedilol different? American Journal of Cardiology 93 7B-12B. (https://doi.org/10.1016/j.amjcard.2004.01.020) 
Pacak K 2007 Preoperative management of the pheochromocytoma patient. Journal of Clinical Endocrinology and Metabolism 92 4069-4079. (https://doi.org/10.1210/jc.2007-1720)

Park WY, Thompson JS, Lee KK \& The Department of Veterans Affairs Cooperative Study \#345 Study Group 2001. Effect of epidural anesthesia and analgesia on perioperative outcomes, a randomized, controlled veterans affairs cooperative study. Annals of Surgery $\mathbf{2 3 4}$ $560-571$.

Pedersen ME \& Cockcroft JR 2007 The vasodilatory beta-blockers. Current Hypertension Reports 9 269-277. (https://doi.org/10.1007/ s11906-007-0050-2)

Poirier L \& Tobe SW 2014 Contemporary use of beta-blockers: clinical relevance of subclassification. Canadian Journal of Cardiology $\mathbf{3 0}$ (Supplement) S9-S15. (https://doi.org/10.1016/j.cjca.2013.12.001)
Tarkkila P \& Isola J 1992 A regression model for identifying patients at high risk of hypotension, bradycardia and nausea during spinal anesthesia. Acta Anaesthesiologica Scandinavica 36 554-558. (https:// doi.org/10.1111/j.1399-6576.1992.tb03517.x)

Wapnir IL, Barnard N, Wartenberg D \& Greco RS 2001 The inverse relationship between microvessel counts and tumor volume in breast cancer. Breast Journal 7 184-188. (https://doi. org/10.1046/j.1524-4741.2001.007003184.x)

Weingarten TN, Welch TL, Moore TL, Walters GF, Whipple JL, Cavalcante A, Bancos I, Young Jr WF, Gruber LM, Shah MZ, et al. 2017. Preoperative levels of catecholamines and metanephrines and intraoperative hemodynamics of patients undergoing pheochromocytoma and paraganglioma resection. Urology 100 131-138.

Received in final form 12 May 2020

Accepted 14 May 2020

Accepted Manuscript published online 9 July 2020 (c) 2020 Society for Endocrinology Published by Bioscientifica Ltd. Printed in Great Britain 